\title{
Recent advances in the management of Duchenne muscular dystrophy
}

\author{
Eugen-Matthias Strehle, Volker Straub
}

The John Walton Muscular Dystrophy Research Centre, Newcastle upon Tyne, UK

\section{Correspondence to} Professor Volker Straub, Institute of Genetic Medicine, Newcastle University, International Centre for Life, Central Parkway, Newcastle upon Tyne NE1 3BZ, UK; volker.straub@ncl.ac.uk

Received 19 April 2015 Revised 4 June 2015 Accepted 9 June 2015 Published Online First 7 July 2015

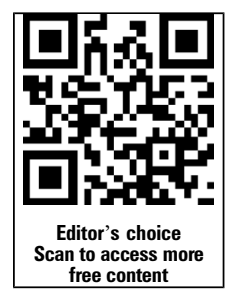

\begin{abstract}
Duchenne muscular dystrophy (DMD) is the commonest inherited neuromuscular disorder of childhood and mainly affects males. Over the course of the last century, the average life expectancy of these patients has doubled and now stands at $\sim 25$ years. This progress has been made possible through advances in the diagnosis, treatment and long-term care of patients with DMD. Basic and clinical research, national and international scientific networks, and parent and patient support groups have all contributed to achieving this goal. The advent of molecular genetic therapies and personalised medicine has opened up new avenues and raised hopes that one day a cure for this debilitating orphan disease will be found. The main purpose of this short review is to enable paediatricians to have informed discussions with parents of boys with DMD about recent scientific advances affecting their child's clinical care.
\end{abstract}

\section{INTRODUCTION}

Duchenne muscular dystrophy is caused by out-of-frame mutations of the dystrophin (DMD) gene on chromosome Xp21 and transmitted in an $\mathrm{X}$-linked recessive fashion but sporadic mutations are common. The mutations result in a deficiency of the protein dystrophin. DMD was first described by the English physician Edward Meryon in $1852 .{ }^{1}$ However, the condition is named after the French neurologist Guillaume-Benjamin-Amand Duchenne who in 1868 reported a case series of boys with 'pseudo-hypertrophic muscular paralysis'. ${ }^{2}$ In 1954, Walton and Natrass published the first comprehensive classification of human myopathies based on 105 patients from the northeast of England. Forty-eight of them (46\%) had DMD and were characterised in great detail. ${ }^{3}$ Other conditions mentioned in their pioneering paper were facioscapulohumeral muscular dystrophy, limbgirdle muscular dystrophy and myotonic dystrophy. Half a century later, Norwood $e t a l^{4}$ presented epidemiological data including 1105 patients from a regional neuromuscular clinic in the north of England that showed a combined prevalence for the dystrophinopathies of 8.46/100 000 total population. The life expectancy of patients with DMD has risen steadily over the last decades thanks to the introduction of new medical and surgical treatments, and a multidisciplinary care approach. ${ }^{5}$ Passamano et al analysed 516 Italian Duchenne patients who were born in the 1960s, 1970s and 1980s. At 25 years of age, their respective survival rates were $13.5 \%, 31.6 \%$ and $49.2 \%{ }^{6}$ Here we will outline the improvements made in diagnosing and caring for patients with DMD during the last few years and highlight key aspects of evolving treatment strategies. Muscular dystrophy research takes place worldwide and is moving fast; therefore, not every aspect of it can be covered in this brief review.

\section{DIAGNOSIS}

Prompt diagnosis of DMD is important so that the available treatment options can be commenced as early as possible. It has been shown that often there is a lapse of 1-2 years between the first symptoms of the disease and the definitive diagnosis. ${ }^{7} 8$ Patients with DMD typically present in early childhood with delayed walking, difficulties in climbing stairs and hopping, a waddling gait or tip toeing. Physical signs include a reduced muscle bulk, pseudo-hypertrophy of the calf muscles and tightening of the Achilles tendons. These clinical features should prompt the clinician to check the child's plasma creatine kinase (CK), which is expressed in muscle and brain cells. The acceptable upper limit for a normal CK is ca. $300 \mathrm{IU} / \mathrm{L}$, whereas CK levels in DMD usually exceed $1000 \mathrm{IU} / \mathrm{L}$ and can be as high as $30000 \mathrm{IU} / \mathrm{L}$. This increase is caused by leakage of the enzyme from the cytoplasm of the damaged muscle fibre into the blood circulation. CK levels are a poor indicator of disease progression and are not routinely measured once the diagnosis has been established. It has been suggested to check the CK level of every newborn so that DMD can be detected at an earlier age than the average of 4 years, but strictly speaking the disease does not fulfil the well-established criteria to justify the introduction of a neonatal screening test. ${ }^{9}$ In the past, the diagnosis was confirmed with a muscle biopsy and histological staining, but after the identification of the dystrophin gene by Louis Kunkel in 1985, molecular genetic testing became available and replaced the muscle biopsy in many diagnostic centres. ${ }^{10} 11$ The DMD gene is $2.4 \mathrm{Mb}$ long and has at least 79 exons, making it the largest known human gene. The mutations leading to DMD tend to be clustered in certain 'hot-spot' regions of the gene. They can be divided into deletions $(\sim 60 \%)$, duplications $(\sim 10 \%)$ and point mutations $(\sim 30 \%)$. Details about the latest developments in genetic testing such as multiplex ligationdependent probe amplification can be gleaned from the textbook chapter on dystrophinopathies by Sinnreich. ${ }^{12}$

\section{PATIENT CARE}

Fifty years ago, Dubowitz described physiotherapy, splints and antibiotics to treat infections as the only treatment available for DMD. ${ }^{13}$ Since then significant progress has been made in the development and application of drugs and other interventions 
that have a beneficial effect on the natural course of DMD and prolong the lives of affected patients (table 1). Recently, Bushby et $a l^{14}{ }^{15}$ published comprehensive consensus guidelines that cover all aspects of managing boys with DMD, which were adopted by the National Institute for Health and Care Excellence (NICE). The guidelines were compiled by a panel of 84 multidisciplinary experts according to the RAND Corporation-University of California Los Angeles Appropriateness Method. These authors state that glucocorticoids (GCs) are currently the only drugs to help maintain muscle strength and function in children with DMD (table 2). The multiple pharmacological effects of GCs on dystrophic muscle fibres are not fully understood; they include stimulation of insulin-like growth factors and modulation of T-cell responses. ${ }^{16}{ }^{17} \mathrm{GCs}$ are tolerated relatively well despite their potential multisystem adverse reactions. Significant weight gain and growth retardation are common, raised blood pressure, glycosuria or pathological fracture is uncommon, and a gastrointestinal lesion or an adrenal crisis is rare. In our supra-regional centre, ca. 95\% of newly diagnosed boys with DMD are commenced on GCs. The main reason for not starting GCs is parental refusal. In ca. 5\% of patients, GCs are discontinued because of uncontrollable adverse events, for instance, exacerbation of pre-existing behavioural difficulties (unpublished data). Daily regimes of prednisolone/prednisone or deflazacort are superior to intermittent regimens in relation to ambulation but carry a higher risk of side effects. ${ }^{18} 19$ To assess and combat osteoporosis, patients should have annual bone density scans (dual-energy $\mathrm{x}$-ray absorptiometry) and take oral biphosphonates (risedronate) and vitamin D supplements. Biphosphonates reduce the loss of bone mass by destroying osteoclasts. ${ }^{20}$ Patients with DMD who take GCs have a reduced risk of developing scoliosis, which is partly due to stunting of growth; nevertheless, some of them will require corrective spinal fusion surgery. So far there are no reports that spinal surgery is hampered by bone fragility, but the overall complication rate of the procedure is $22 \%$, wound infection being the commonest. ${ }^{21}$ DMD eventually leads to contractures of the large joints due to progressive wasting and imbalance of flexor and extensor muscles. This inevitable process can be slowed down significantly through daily physiotherapy by a health professional or a trained carer. Boys with DMD require regular cardiovascular assessments to detect a reduction in the

Table 1 Key standards of care for Duchenne muscular dystrophy

\begin{tabular}{|c|c|}
\hline Organ system & Intervention \\
\hline Muscular & $\begin{array}{l}\text { Regular specialist health assessments, physiotherapy, } \\
\text { glucocorticoids, orthoses, wheelchair, hoist, electric bed, } \\
\text { prevention of malignant hyperthermia }\end{array}$ \\
\hline Respiratory & $\begin{array}{l}\text { Immunisations, treatment of respiratory tract infections, lung } \\
\text { function monitoring, pulse oximetry study, cough assistance } \\
\text { device, non-invasive ventilation, tracheostomy }\end{array}$ \\
\hline Cardiovascular & $\begin{array}{l}\text { Cardiovascular assessments with ECHO, ECG, blood pressure } \\
\text { measurements, treatment of cardiomyopathy with ACE } \\
\text { inhibitors and } \beta \text {-blockers }\end{array}$ \\
\hline Gastrointestinal & $\begin{array}{l}\text { Monitoring diet, teeth, swallowing, bowel function and weight } \\
\text { gain, acid reducers, videofluoroscopy, gastrostomy }\end{array}$ \\
\hline Skeletal & $\begin{array}{l}\text { Bone density tests (DXA), calcium, vitamin } \mathrm{D}, \\
\text { bisphosphonates, surgery for scoliosis and joint contractures }\end{array}$ \\
\hline Renal/urogenital & $\begin{array}{l}\text { Prevention and treatment of dehydration, myoglobinuria and } \\
\text { enuresis, urinalyses }\end{array}$ \\
\hline Nervous & $\begin{array}{l}\text { Speech and language assessment, pain and sleep control, } \\
\text { learning and psychosocial support, cataract screening }\end{array}$ \\
\hline
\end{tabular}

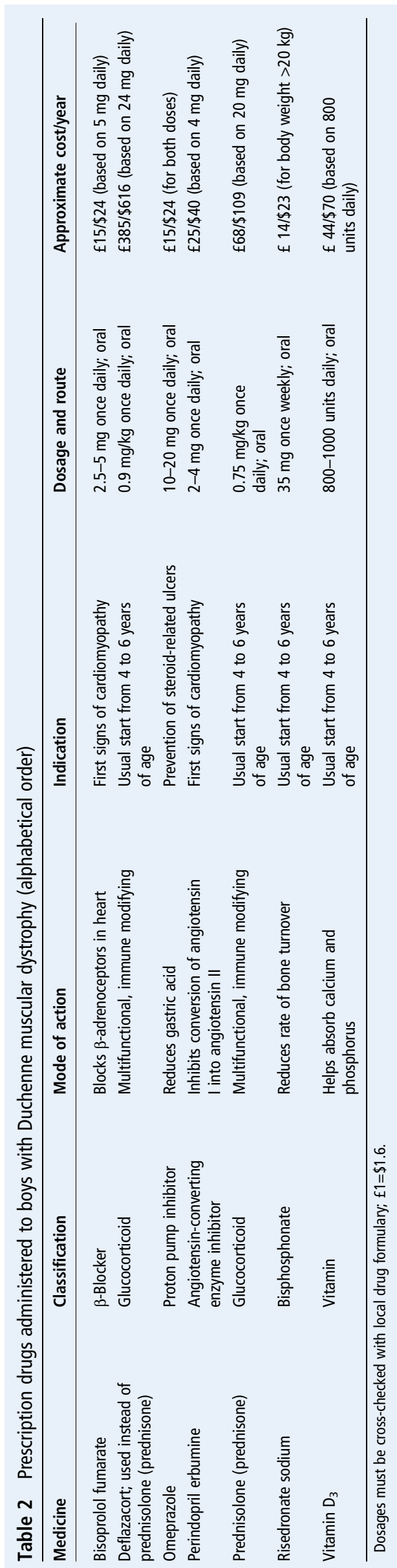


left ventricular ejection fraction early. Although most patients with DMD develop dilated cardiomyopathy, the severity and the age of onset vary significantly and are unrelated to the individual dystrophin gene mutation. ${ }^{22} \mathrm{~A}$ recent randomised, double-blind trial compared the ACE inhibitor lisinopril and the angiotensin II receptor blocker losartan in the treatment of DMD cardiomyopathy and found similar degrees of improvement after 1 year. ${ }^{23}$ $\beta$-Blockers are frequently prescribed alongside ACE inhibitors to treat heart failure but should be used cautiously in patients with asthma. Second-generation $\beta$-blockers mainly inhibit $\beta 1$-receptors, which are predominant in the heart. Several studies involving Duchenne patients with cardiomyopathy have shown an improvement of left ventricular ejection fraction and reduced mortality after treatment with bisoprolol or carvedilol. ${ }^{24}{ }^{25}$ It remains to be seen whether cardioprotective treatment at the point of diagnosis of DMD would be advantageous for these children. ${ }^{26}{ }^{27}$ Iodice $e t a l^{28}$ describe the use of a left ventricular assist device in adolescents with DMD and end-stage heart failure as latest therapeutic development. Good respiratory care including influenza vaccination, lung function measurement and antibiotic treatment when required helps to delay the institution of non-invasive nocturnal ventilation. ${ }^{15}$ The value of dietetic advice and psychosocial support, particularly during the transition from adolescence into adulthood, cannot be stressed enough. ${ }^{14} \mathrm{DMD}$ is a rare disease, which means that these patients should preferably be managed in tertiary centres with the necessary resources and expert staff. This does, however, not exclude shared-care arrangements with local professionals; in fact, they constitute a vital part in the comprehensive and holistic management of boys with DMD. With the increasing lifespan seen in this patient group, more research studies on quality-of-life issues are emerging. It is well known that children with DMD do not experience their life as unhappy, which is probably due to the fact that they have physical difficulties from an early age and consider this to be normal for them. ${ }^{29}$ Some studies among adults with DMD appear to confirm these views, ${ }^{30}$ whereas others paint a less positive picture. ${ }^{31} 32$ The quality of life of the caregivers has also to be taken into account. ${ }^{33}$

To conduct randomised controlled research trials with adequate patient numbers, academic medical centres have to collaborate nationally and globally. Examples of such networks are the UK-based North Star network, ${ }^{34}$ the global TREAT-NMD Alliance ${ }^{35}$ and the US-based network Cooperative International Neuromuscular Research Group. ${ }^{36}$ Parent support groups have been instrumental in promoting the cause of DMD, for instance, the Muscular Dystrophy Campaign (UK) and the Muscular Dystrophy Association (USA). Using standardised care guidelines not only benefits patients directly but also enables researchers to obtain better research data. ${ }^{37}$

\section{CLINICAL RESEARCH}

The last two decades have seen increasing efforts to find and test novel drug treatment for DMD by applying some of the methodologies listed in table 3. Currently, so-called 'small

Table 3 Experimental treatments for Duchenne muscular dystrophy

\begin{tabular}{ll}
\hline Method & \\
\hline Cell membrane repair & Exon skipping \\
Gene repair & Gene transfer \\
Muscle or stem cell therapy & Myostatin inhibition \\
Stop codon read through & Utrophin upregulation
\end{tabular}

molecule therapies' that interfere with specific gene mutations carried by subgroups of boys with DMD appear to be the most promising candidates (personalised medicine). ${ }^{38}$ Ataluren (PTC124) is a polycyclic organic molecule that reduces the sensitivity of ribsosomes towards premature stop codons, resulting in a so-called 'stop-codon read-through'. ${ }^{39}$ Questions have been raised in the scientific community as to whether ataluren's mechanism of action is real. ${ }^{40}$ In 2014 , the drug was approved under the brand name Translarna by the European Medicines Agency and the European Commission for treatment of DMD caused by nonsense mutations, which account for ca. 13\% of mutations. ${ }^{41}$ Bushby et $a l^{42}$ conducted a double-blind, randomised, placebo-controlled multicentre trial of oral ataluren involving 173 patients with DMD aged 5-20 years. After 48 weeks of treatment, study subject on $40 \mathrm{mg} / \mathrm{kg} /$ day ataluren but not those on $80 \mathrm{mg} / \mathrm{kg} /$ day showed a slower decline in their walking distance $(-13 \mathrm{~m})$ compared with the placebo group $(-44 \mathrm{~m})$. No serious adverse events were observed. Currently, a phase III trial of ataluren is underway, which should provide clarity regarding its efficacy or lack of it.

Exon skipping with antisense oligonucleotides (AON, morpholinos) is another gene-modifying technique trialled in patients with DMD. AON are short nucleic acid analogues that attach themselves to messenger RNA or single-stranded DNA and prevent its translation into a protein, effectively silencing part of a gene. In the context of DMD, AON have been designed to target mutation-containing exons in one of the 'hot-spots' of the dystrophin gene. Normally, an out-of-frame mutation leads to a stop of dystrophin expression and the more severe DMD phenotype. However, by skipping the deleted or duplicated exon, the out-of-frame mutation is turned into an in-frame mutation. Dystrophin expression can therefore continue at a reduced level, which results in the milder Becker muscular dystrophy. ${ }^{43}{ }^{44}$ Drisapersen is an AON that causes skipping of exon 51, which is a therapeutic strategy applicable to $13 \%$ of boys with DMD. It has been tested in three double-blind, placebo-controlled trials (DEMAND studies). In one 48-week study, drisapersen was administered subcutaneously at a dose of $6 \mathrm{mg} / \mathrm{kg}$ weekly to 18 patients (continuous regimen); another group of 17 patients received nine doses of drisapersen over 6 weeks followed by a 4-week break (intermittent regimen); and one group of 18 was given placebo. After 24 weeks but not at 48 weeks, the continuous regimen resulted in a statistically significant increase in walking distance $(\sim 35 \mathrm{~m})$ compared with placebo. Proteinuria was a common adverse effect. ${ }^{45}{ }^{46}$ Eteplirsen is a morpholino drug that leads to removal of exon 51 during the RNA splicing process (excision of introns and joining of exons). The resulting dystrophin protein is functional but shorter than the normal one. ${ }^{47} 48$ Mendell et al enrolled 12 boys with DMD on GCs in a double-blind trial and divided them into three groups. One group received $30 \mathrm{mg} / \mathrm{kg}$ intravenous eteplirsen weekly, another $50 \mathrm{mg} / \mathrm{kg}$ weekly and a third group placebo. The patients had up to three muscle biopsies throughout the 48 -week trial period. The boys in the eteplirsen groups showed increased dystrophin production of $40-50 \%$ on biopsy and were able to walk $\sim 67 \mathrm{~m}$ further than control after 48 weeks of treatment. The drug was well tolerated. ${ }^{49}$ It must be stressed that at the time of writing all types of gene-modifying therapies for DMD were at the experimental stage.

Survival rates are the ultimate outcome measure for many diseases including DMD. However, proving a reduction of mortality within time-limited clinical intervention studies is difficult, especially if the illness is progressing slowly. Researchers are continuously striving to develop more accurate and reliable 
clinical tests and laboratory parameters that can be used as study endpoints and prognostic indicators. ${ }^{50}$ Among others, the following assessments and investigations have been found useful for determining clinical outcomes and monitoring disease progress in patients with DMD: 6-min walk test, ${ }^{51}$ timed function test, North Star ambulatory assessment, ${ }^{52}$ muscle ultrasound, ${ }^{53}$ MRI and spectroscopy of pelvis and legs, ${ }^{54} 55$ and analysis of muscle biopsies with a variety of techniques. ${ }^{56}$ The 6-min walk test score and the North Star ambulatory assessment score show a gradual decline in patients with DMD from the age of 7 years. It has been suggested that a difference of $30 \mathrm{~m}$ in the 6-min walk test represents a clinically meaningful result even though it may not be statistically significant. ${ }^{57}$ Recently, microRNAs have become a focus of interest in DMD research. These short RNA molecules are present in mammalian blood and organ tissue, and have a regulatory function. Their expression levels in health and disease vary, which makes them likely candidates as valid future biomarkers. ${ }^{58}$ Nowadays the storage of human tissue (eg, blood, muscle, skin, DNA) is tightly controlled and requires written consent from the patient or legal guardian. Storage banks such as UK Biobank and EuroBioBank play a vital role for research into muscular dystrophy.

\section{CONCLUSION}

Causative treatment of monogenic genetic diseases (Mendelian disorders) is one of the great challenges of modern medicine. Gene therapy has the potential to solve this problem, but it is still in its infancy despite several decades of intense research. Germline gene therapy is prohibited in the UK and many other countries due to ethical concerns, whereas somatic cell gene therapy is available for selected patients within research trials. The NICE (http://www.nice.org) does not recommend gene therapy for any medical condition. The USA does not have specific laws restricting research on gene therapy, but the Food and Drug Administration has yet to approve the first genemodifying agent (Glybera for the treatment of lipoprotein lipase deficiency could be the first one). Drug costs are another important factor to take into consideration. According to the Kings Fund and the Nuffield Trust, the British government's annual budget for the National Health Service will remain static or decrease rather than increase during the coming years. ${ }^{59} 60$ Pharmaceutical companies invest large resources in the development of gene-modifying agents and naturally hope to make a profit from their new products. It is estimated that any type of drug acting on the dystrophin gene will cost in excess of $£ 100000$ ( $\$ 160000$ ) per patient per year. These costs have to be weighed against the economic burden of the disease. ${ }^{61}$ Landfeldt et al studied 770 patients with DMD in Germany, Italy, the UK and the USA. They found that the estimated annual costs per patient (direct, indirect and intangible costs) ranged from $£ 53000$ to $£ 79000$ (\$80 000—\$121 000). ${ }^{62}$ One would like to see strong evidence that such expensive novel drugs are of definite overall benefit to patients with DMD, for instance, by reducing morbidity and mortality or by reaching a validated surrogate endpoint. Unfortunately as yet there is insufficient evidence that any of the newly developed drugs can achieve this desirable outcome. Furthermore, somatic gene-modifying therapy, should it eventually become available, is likely to remain an adjunct to standard treatment rather than a stand-alone therapy that will add to the overall costs of patient care. In medicine, scientific progress tends to occur in small steps rather than big leaps, and setbacks are far more common than breakthroughs. Approximately 9 out of 10 clinical pharmacological trials have negative outcomes. However, each study adds a new piece of

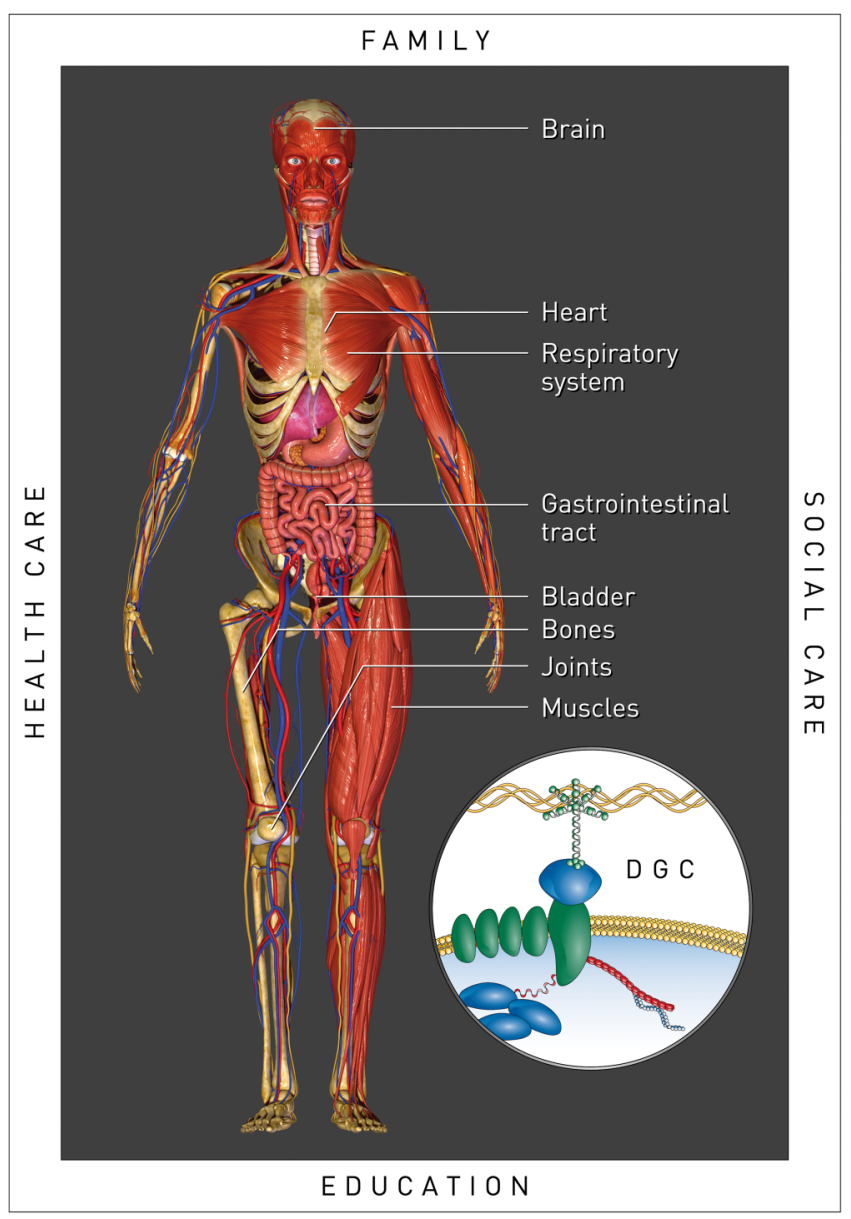

Figure 1 Diagram illustrating the multisystem character of Duchenne muscular dystrophy that is caused by a defect in the dystrophinglycoprotein complex (DGC); the patient is integrated in a multidisciplinary support system.

knowledge and helps to solve the giant jigsaw of finding a lasting cure. Although recent clinical research trials in the field of DMD have shown some promising results, there is a long way to go before effective gene therapy will become available for children living in economically developed countries. ${ }^{63} 64$ Until such time standardised conventional therapy and regular monitoring by a dedicated team of healthcare specialists should remain the cornerstone of DMD management (figure 1). ${ }^{65}$

Acknowledgements The authors would like to thank the paediatric muscle team at the Institute of Human Genetics in Newcastle for their support; and Angela Butler/7activestudio for preparing figure 1. Clinical research could not take place without close involvement of patients with DMD and their families who volunteer to participate in trials and give permission for invasive procedures.

Contributors E-MS and VS have jointly written and agreed the manuscript.

Competing interests VS is or has been a principal investigator for trials sponsored by Genzyme/Sanofi, GSK, Prosensa/Biomarin, ISIS Pharmaceuticals and Sarepta. He received speaker honoraria from Genzyme/Sanofi, is a member of the international Pompe advisory board of Genzyme/ Sanofi, and has been on advisory boards for Acceleron Pharma, Audentes, Italfarmaco S.p.A., Nicox, Pfizer, Prosensa, Santhera and TrophyNOD. He also has a research collaboration with Ultragenyx and Genzyme/Sanofi.

Provenance and peer review Commissioned; externally peer reviewed.

\section{REFERENCES}

1 Emery AE, Emery ML. Edward Meryon (1809-1880) and muscular dystrophy. J Med Genet 1993;30:506-11.

2 Rondot PGBA. Duchenne de Boulogne (1806-1875). J Neurol 2005;252:866-7. 
3 Walton JN, Nattrass FJ. On the classification, natural history and treatment of the myopathies. Brain 1954;77:169-231.

4 Norwood FL, Harling C, Chinnery PF, et al. Prevalence of genetic muscle disease in Northern England: in-depth analysis of a muscle clinic population. Brain 2009; 158:3175-86.

5 Manzur AY, Kinali M, Muntoni F. Update on the management of Duchenne muscular dystrophy. Arch Dis Child 2008;93:986-90.

6 Passamano L, Taglia A, Palladino A, et al. Improvement of survival in Duchenne Muscular Dystrophy: retrospective analysis of 835 patients. Acta Myol 2012;31:121-5.

7 Quinlivan R. Early diagnosis of Duchenne muscular dystrophy is essential improve long term outcomes. Arch Dis Child 2014;99:1061.

8 Van Ruiten HJ, Straub V, Bushby K, et al. Improving recognition of Duchenne muscular dystrophy: a retrospective case note review. Arch Dis Child 2014;99:1074-7.

9 Scully MA, Farrell PM, Ciafaloni E, et al. Cystic fibrosis newborn screening: a model for neuromuscular disease screening? Ann Neurol 2015;77:189-97.

10 Hoffman EP. Dystrophinopathies. In: Karpati G, Hilton-Jones D, Griggs RC, eds. Disorders of voluntary muscle. 7th edn. Cambridge: Cambridge University Press, 2001:385-432

11 Kunkel LM. 2004 William Allen Award address. Cloning of the DMD gene. Am J Hum Genet 2005;76:205-14.

12 Sinnreich M. Dystrophinopathies. In: Karpati G, Hilton-Jones D, Bushby K, Griggs RC, eds. Disorders of voluntary muscle. 8th edn. Cambridge: Cambridge University Press, 2010:205-29.

13 Dubowitz V. Muscular dystrophy and related disorders. Postgrad Med J 1965;41:332-46.

14 Bushby K, Finkel R, Birnkrant DJ, et al. Diagnosis and management of Duchenne muscular dystrophy, part 1: diagnosis, and pharmacological and psychological management. Lancet Neurol 2010;9:77-93.

15 Bushby K, Finkel R, Birnkrant DJ, et al. Diagnosis and management of Duchenne muscular dystrophy, part 2: implementation of multidisciplinary care. Lancet Neurol 2010;9:177-89.

16 Angelini $C$, Peterle E. Old and new therapeutic developments in steroid treatment in Duchenne muscular dystrophy. Acta Myol 2012;31:9-15.

17 Flanigan KM, Campbell K, Viollet L, et al. Anti-dystrophin T cell responses in Duchenne muscular dystrophy: prevalence and a glucocorticoid treatment effect. Hum Gene Ther 2013;24:797-806.

18 Ricotti V, Ridout DA, Scott E, et al. Long-term benefits and adverse effects of intermittent versus daily glucocorticoids in boys with Duchenne muscular dystrophy. J Neurol Neurosurg Psychiatry 2013;84:698-705.

19 Griggs RC, Herr BE, Reha A, et al. Corticosteroids in Duchenne muscular dystrophy: major variations in practice. Muscle Nerve 2013;48:27-31.

20 Gordon KE, Dooley JM, Sheppard KM, et al. Impact of biphosphonates on survival for patients with Duchenne muscular dystrophy. Pediatrics 2011;127:e353-8.

21 Duckworth AD, Mitchell MJ, Tsinkos Al. Incidence and risk factors for post-operative complications after scoliosis surgery in patients with Duchenne muscular dystrophy: a comparison with other neuromuscular conditions. Bone Joint J 2014;96:943-9.

22 Ashwath ML, Jacobs IB, Crowe CA, et al. Left ventricular dysfunction in Duchenne muscular dystrophy and genotype. Am J Cardiol 2014;114:284-9.

23 Allen HD, Flanigan KM, Thrush PT, et al. A randomized, double-blind trial of lisinopril and losartan for the treatment of cardiomyopathy in Duchenne muscular dystrophy. PLOS Curr 2013;5.

24 Politano L, Nigro G. Treatment of dystrophinopathic cardiomyopathy: review of the literature and personal results. Acta Myol 2012;31:24-30.

25 Matsumara T. Beta-blockers in children with Duchenne muscular dystrophy. Rev Recent Clin Trials 2014.

26 Blain A, Greally E, Laval S, et al. Beta-blockers, left and right ventricular function, and in-vivo calcium influx in muscular dystrophy cardiomyopathy. PLoS ONE 2013;8:e57260.

27 Janssen PM, Murray JD, Schill KE, et al. Prednisolone attenuates improvement of cardiac and skeletal contractile function and histopathology by lisinopril and spironolactone in the $\mathrm{mdx}$ mouse model of Duchenne muscular dystrophy. PLOS ONE 2014:9:e88360.

28 Iodice $F$, Testa G, Averardi M, et al. Implantation of a left ventricular assist device as a destination therapy in Duchenne muscular dystrophy with end stage cardiac failure: Management and lessons learned. Neuromuscul Disord 2015;25:19-23.

29 Bothwell JE, Dooley JM, Gordon KE, et al. Duchenne muscular dystrophy — parental perceptions. Clin Pediatr (Phila) 2002;41:105-9.

30 Rahbek J, Werge B, Madsen A, et al. Adult life with Duchenne muscular dystrophy: observations among an emerging and unforeseen patient population. Pediatr Rehabil 2005;8:17-28.

31 Pangalila RF, van den Bos GA, Bartels B, et al. Quality of life of adult men with Duchenne muscular dystrophy in the Netherlands: implications for care. J Rehabil Med 2015:47:161-6.

32 Pangalila RF, van den Bos GA, Bartels B, et al. Prevalence of fatigue, pain, and affective disorders in adults with Duchenne muscular dystrophy and their associations with quality of life. Arch Phys Med Rehabil 2015. Published Online First. doi:10.1016/j.apmr.2015.02.012

33 Nozoe KT, Polesel DN, Moreira GA, et al. Sleep quality of mother-caregivers of Duchenne muscular dystrophy patients. Sleep Breath 2015. Published Online First.
34 Mayhew A, Cano S, Scott E, et al. Moving towards meaningful measurement: Rasch analysis of the North Star Ambulatory Assessment in Duchenne muscular dystrophy. Dev Med Child Neurol 2011;53:534-42.

35 Bladen CL, Salgado D, Monges S, et al. The TREAT-NMD DMD Global Database: analysis of more than 7000 Duchenne muscular dystrophy mutations. Hum Mutat 2015;36:395-402.

36 Spurney C, Shimizu R, Morgenroth LP, et al. Cooperative International Neuromuscular Research Group Natural History Study demonstrates insufficient diagnosis and treatment of cardiomyopathy in Duchenne muscular dystrophy. Muscle Nerve 2014:50:250-6.

37 Landfeldt $E$, Lindgren $P$, Bell CF, et al. Compliance to care guidelines for Duchenne muscular dystrophy. J Neuromuscul Dis 2015;2:63-72.

38 Flanigan KM. Duchenne and Becker muscular dystrophies. Neurol Clin 2014;32:671-88,

39 Peltz SW, Morsy M, Welch EM, et al. Ataluren as an agent for therapeutic nonsense suppression. Annu Rev Med 2013;64:407-25.

40 McElroy SP, Nomura T, Torrie SL, et al. A lack of premature termination codon read-through efficacy of PTC124 (Ataluren) in a diverse array of reporter assays. PLoS Biol 2013;11:e1001593.

41 Ryan NJ. Ataluren: first global approval. Drugs 2014;74:1709-14.

42 Bushby $K$, Finkel $R$, Wong $B$, et al. Ataluren treatment of patients with nonsense mutation dystrophinopathy. Muscle Nerve 2014;50:477-87.

43 Wood MJ. To skip or not to skip: that is the question for Duchenne muscular dystrophy. Mol Ther 2013;21:2131-2.

44 Findlay AR, Wein N, Kaminoh, et al. Clinical phenotypes as predictors of the outcome of skipping around DMD exon 45. Ann Neurol 2015;77:668-74.

45 Flanigan $\mathrm{KM}$, Voit T, Rosales $\mathrm{XQ}$, et al. Pharmacokinetics and safety of single doses of drisapersen in non-ambulant subjects with Duchenne muscular dystrophy: results of a double-blind randomized clinical trial. Neuromuscul Disord 2014;24:16-24.

46 Voit T, Topaloglu H, Straub V, et al. Safety and efficacy of drisapersen for the treatment of Duchenne muscular dystrophy (DEMAND II): an exploratory, randomised placebo-controlled phase 2 study. Lancet Neurol 2014;13:987-96.

47 Ruegg UT. Pharmacological prospects in the treatment of Duchenne muscular dystrophy. Curr Opin Neurol 2013;26:577-84.

48 Cirak S, Feng L, Anthony K, et al. Restoration of the dystrophin-associated glycoprotein complex after exon skipping therapy in Duchenne muscular dystrophy. Mol Ther 2012;20:462-7.

49 Mendell JR, Rodino-Klapac LR, Sahenk $Z$, et al. Eteplirsen for the treatment of Duchenne muscular dystrophy. Ann Neurol 2013;74:637-47.

50 Bushby K, Connor E. Clinical outcome measures for trials in Duchenne muscular dystrophy: report from International Working Group meetings. Clin Investig (London) 2011;1:1217-35

51 Goemans N, Klingels K, van den Hauwe M, et al. Six-minute walk test: reference values and prediction equation in healthy boys aged 5 to 12 years. PLOS ONE 2013:8:e84120.

$52 \mathrm{McD}$ onald $\mathrm{CM}$, Henricson EK, Abresch RT, et al. The cooperative international neuromuscular research group Duchenne natural history study—a longitudinal investigation in the era of glucocorticoid therapy: design of protocol and the methods used. Muscle Nerve 2013:48:32-54.

53 Shklyar I, Geisbush TR, Mijialovic AS, et al. Qualitative muscle ultrasound in Duchenne muscular dystrophy: a comparison of techniques. Muscle Nerve 2015;51:207-13

54 Forbes SC, Wilcocks RJ, Triplett WT, et al. Magnetic resonance imaging and spectroscopy assessment of lower extremity skeletal muscles in boys with Duchenne muscular dystrophy: a multicentre cross sectional study. PLosS ONE 2014;9:e106435.

55 Kinali M, Arechavala-Gomeza V, Cirak S, et al. Muscle histology vs MRI in Duchenne muscular dystrophy. Neurology 2011;25:346-53.

56 Dubowitz V, Sewry CA, Olfors A. Muscle biopsy: a practical approach. 4th edn. Philadelphia: Saunders Ltd, 2013.

57 Lynn S, Aartsma-Rus A, Bushby K, et al. Measuring clinical effectiveness of medicinal products for the treatment of Duchenne muscular dystrophy. Neuromuscul Disord 2015;25:96-105.

58 Alexander MS, Kunkel LM. Skeletal muscle microRNAs: their diagnostic and therapeutic potential in human muscle diseases. I Neuromuscul Dis 2015;2:1-11.

59 Appleby J. Spending on health and social care over the next 50 years. Why think long term? London: The King's Fund, 2013.

60 Jones NM, Charlesworth A. The anatomy of health spending 2011/2012. London: Nuffield Trust, 2013.

61 Schreiber-Katz O, Klug C, Thiele S, et al. Comparative cost of illness analysis and assessment of health care burden of Duchenne and Becker muscular dystrophies in Germany. Orphanet I Rare Dis 2014;9:210.

62 Landfeldt $\mathrm{E}$, Lindgren $\mathrm{P}$, Bell CF, et al. The burden of Duchenne muscular dystrophy: an international cross-sectional study. Neurology 2014;83:529-36.

63 Fairclough RJ, Wood MJ, Davies KE. Therapy for Duchenne muscular dystrophy: renewed optimism from genetic approaches. Nat Rev Genet 2013;14:373-8.

64 Al-Zaidy S, Rodino-Klapac L, Mendell JR. Gene therapy for muscular dystrophy: moving the field forward. Pediatr Neurol 2014;51:607-18.

65 Strehle EM. Long-term management of children with neuromuscular disorders. J Pediatr (Rio J) 2009;85:379-84. 